\title{
Application of Brushless Dc Motor in the Production Delivery System
}

\author{
Yao $\mathrm{Yu}^{1, *}$ and Yunfei Fan ${ }^{2}$ \\ ${ }^{I} M \& E$ College, Agriculture University of Hebei, Baoding 071001, China \\ ${ }^{2}$ Office of Academic Affairs, Agriculture University, Baoding 071001, China
}

\begin{abstract}
The product delivery system is normally powered by a DC motor. Permanent magnet brushless DC motor small sized, high power density, simple structure, is currently being widely used in a variety of transmission systems. In this paper, a permanent magnet motor position sensorless actuator for the production of a delivery system is studied. The actuator position control algorithm of the EGR system of the DC motor is studied and the lag characteristic test is carried out. Through the use of symmetrical triangular wave duty cycle input and output control signals. The corresponding duty cycle characteristics of the switch indicate that the actuator has a significant hysteresis characteristic and should not be used in an open loop control. A double closed-loop control algorithm has been design, including two control loop position loops and current loops, to study the PT1 filtering algorithm and the anti-saturation PID algorithm of the basic control module. The stepping test and steady-state test results show that the steady-state error of the control algorithm can achieve fast and smaller step response.
\end{abstract}

Keywords: Production delivery system, Permanent magnet brushless dc, Rotor, Optimization design.

\section{INTRODUCTION}

Brushless DC motor (BLDCM) has the advantages of simple structure, reliable operation, high power density, good speed performance, good mechanical properties and so on, and so has been widely used. However, there is torque ripple in the operation of BLDCM, which greatly limits its application in the servo system [1]. So suppressing or eliminating torque ripple is becoming the key to improving BLDCM performance. At present, domestic and foreign scholars on the BLDCM control strategy for a lot of in-depth study, put forward a variety of control means. However, because BLDCM is a nonlinear system, multivariable, strong coupling, the use of classical control theory is difficult to meet the actual requirements, intelligent control system with self-learning, adaptive, self-organization and other functions, can solve the model uncertainty, nonlinear control and other complex issues. Therefore, the use of modern intelligent control strategy has become the development trend of BLDCM [2].

\section{THE STRUCTURE AND WORKING PRINCIPLE OF BLDCM}

Brushless DC motor consists of three parts: the motor body, the rotor position detection device and electronic phase change device [3]. BLDCM works as is shown in Fig. (1). When the magnetic field generated by the stator winding interacts with the magnetic field generated by the magnetic field generated by the rotor winding, the position sensor of the rotor converts the mechanical signal into an

\footnotetext{
*Address correspondence to this author at Ling yusi Road, M\&E College, Agriculture University of Hebei, Baoding 071001, China;

Tel: +8613831222510; E-mail: younger1981@yeah.net
}

electrical signal and controls the frequency converter so that the stator windings of each phase change according to a certain number of turns. The stator current changes with the rotor position, and in a certain order for the direction. The inverter conduction sequence and rotor angle synchronization will be mechanical leading to brush DC motor phase conversion [4].

\section{BRUSHLESS DC MOTOR TECHNOLOGY}

The product delivery system consists of a motor, a drive and a conveyor. The motor is responsible for converting electrical energy into mechanical energy. Permanent magnet brushless DC motor has a small size, high performance, simple structure and power. Today, in the automotive industry, motors are being widely used, such as DC micro motors, which can control hundreds of cars. DC motor brush is one of the biggest problems in using this type of motor, the presence of brushes is to make the motor volume change, and after the long-term use brush also needs to be replaced. Brushless DC motor, through the electronic circuit to control the motor commutation, thus eliminating the mechanical rectifier, does not need to replace the brush which ensures a great extension of the motor life [5].

Compared with ordinary DC motor, brushless DC motor can not work directly, so the motor must run through the electronic components to control the motor inverter voltage, current and conduction sequence of each phase winding. The product delivery system power drive system is shown in Fig. (2). 

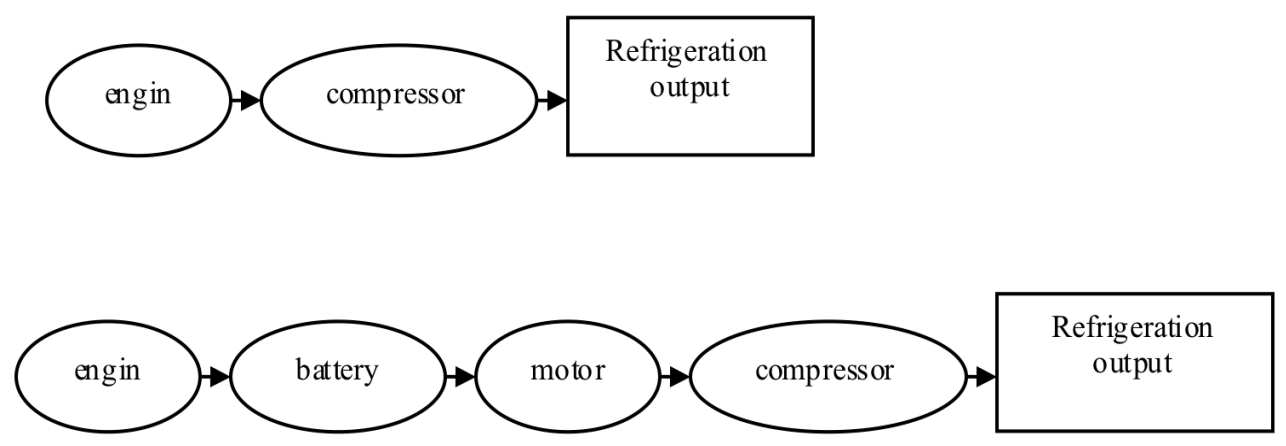

Fig. (1). The working principle of BLDCM.

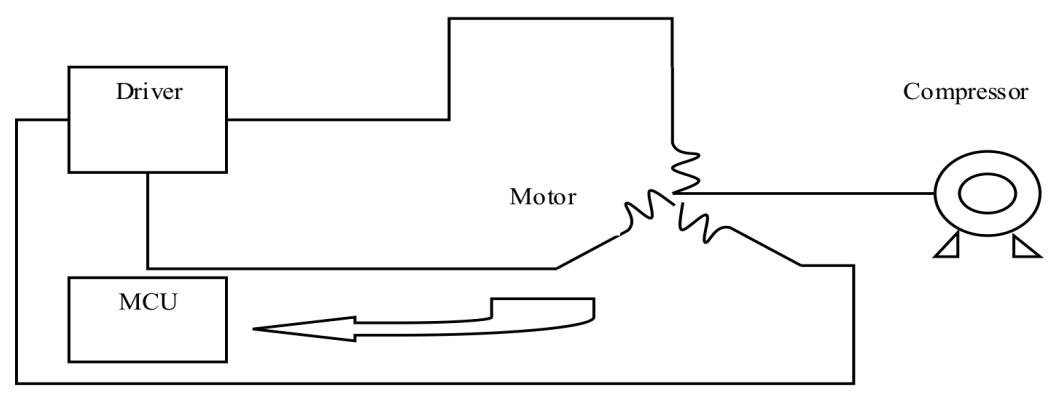

Fig. (2). Electric drive system of the production delivery schemes.

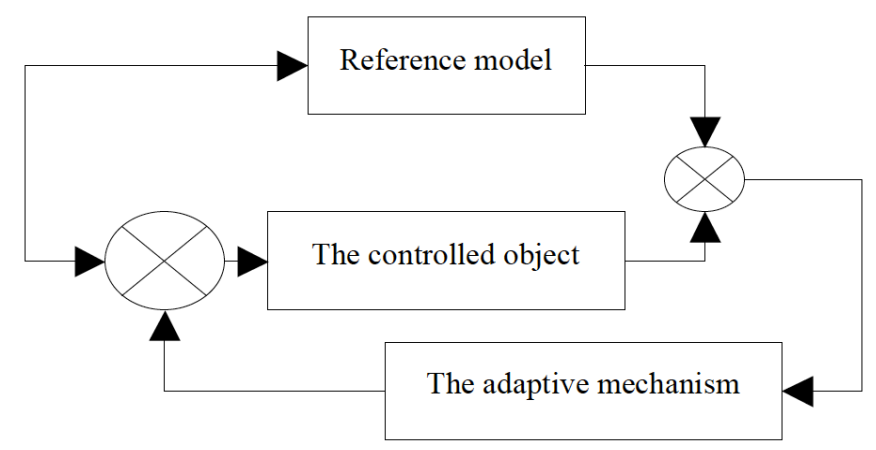

Fig. (3). The basic structure of the MRAC system.

Today, the application of high speed and high power amplifiers for brushless DC motors has become a trend. In the product delivery system, reducing the size of the motor and the compressor has a positive meaning. Embedded permanent magnet motor with high efficiency, small size, power density, solid structure, weak magnet and so on, is suitable for brushless DC motor applications. Although the motor magnets are inserted directly into the internal shoe to protect the function of the magnet, the mechanical stress and strength of the motor are not reduced. [6].

\section{INTELLIGENT CONTROL OF BLDCM}

\subsection{Model Reference Adaptive Control}

Model Reference Adaptive Control (MRAC) is an adaptive control that is currently considered one of the most mature applications. The basic principle of MRAC is that the output of the object and the reference model pro- duces the desired phase comparison by generating the error signal. MRAC does not require a mathematical model of the controlled object, does not require parameter identification, and is easy to implement adaptive speed. MRAC has a simulation application of a control system with a dualloop BLDCM drive system, that is, a hysteresis current controller with a loop speed from the outer ring and other currents from the inner ring. MRAC control has better static and dynamic performance than PI control. The system structure is shown in Fig. (3).

\subsection{Fuzzy Control}

Fuzzy control does not depend on the object model. It uses language variables to describe the system characteristics, and in the dynamic information system and fuzzy control rules on the basis of appropriate control, achieved a good dynamic response. Hardware is relatively simple and powerful. At present, the basic fuzzy control usually in- 


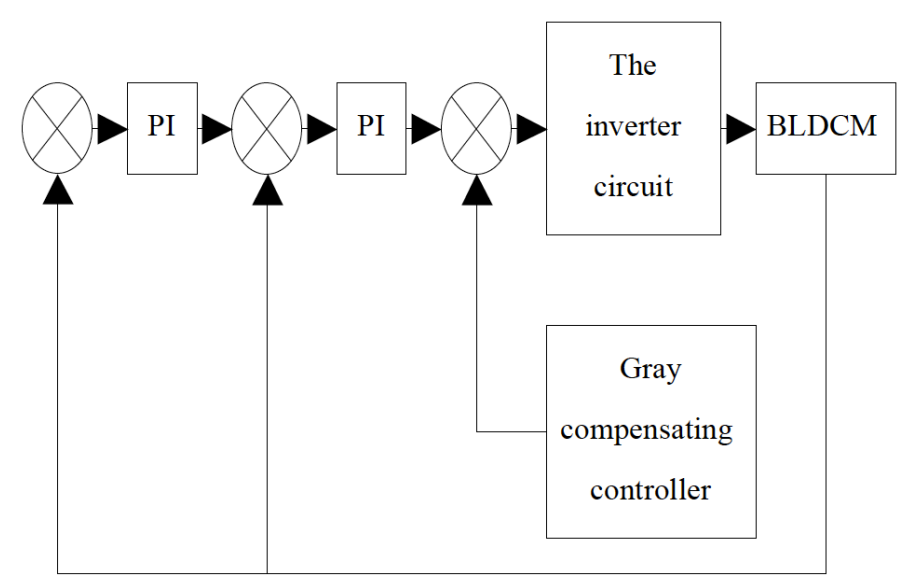

Fig. (4). BLDC control system structure diagram of the current hysteresis loop

cludes fuzzy PID control, fuzzy PID dual control and adaptive fuzzy PID control. Fuzzy PID dual control principle is to set the error set value, according to the feedback value error size, to achieve fuzzy PID control and reference value of the switch. The control system has good dynamic and steady state performance to achieve fuzzy control and PID control complementary advantages. Fuzzy adaptive PID control principle is to use the PID controller fuzzy rules and parameters to achieve on-line self-tuning, improving the performance of PID controller. In order to solve this problem, many scholars use modern optimization algorithm to optimize fuzzy control rules, such as genetic algorithm, neural network algorithm, particle swarm algorithm, ant colony algorithm. Genetic algorithm is used to optimize the fuzzy control rules and obtain fuzzy rule optimization. The simulation results show that the method can improve the anti - jamming ability of the system [7].

\subsection{The Grey Control}

Gray prediction system control is based on the uncertainty of gray system theory control method. The gray prediction method includes known information and uncertain information. Due to BLDCM's own parameters and uncertain external disturbances, the BLDCM mathematical model can be divided into deterministic and indeterminate parts. The uncertainty of the gray model consists of a controlled object, a gray predictor, and a grayscale control system to achieve a certain degree of contrast. The simulation results show that the control performance of the linear motor control mode is better than that of the traditional control mode without load or load change, and the dynamic response is good and the anti - jamming performance is good [8]. BLDCM control system current hysteresis loop gray scale control is shown in Fig. (4).

\section{DOUBLE CLOSED-LOOP POSITION CON- TROL ALGORITHM}

\subsection{Double Closed-Loop Position Control Algorithm}

The control algorithm includes two parts: the position control loop and the current control loop, each including the original closed-loop control target value, the filter target value, the measured value, the error and the control output variable. The main processing algorithms include filter algorithm and PID control algorithm. For the position control loop, after the filter obtains the filtered target value, the actuator sensor measures the difference between the target value $\Delta \mathrm{I}$ and the measured current $\mathrm{P}$, and uses the PID algorithm to calculate the output current value of the target position control loop. Current control loop's original goal is to measure the current control error, and finally into the PID algorithm to calculate the duty cycle output [9].

\subsection{PT1 Filter Module}

The $P T_{1}$ algorithm is mainly used for filtering, namely to remove high frequency input signal disturbance. The discrete difference equation is as follows:

$$
Y_{k}=a Y_{k-1}+(1-a) X_{k-1}
$$

In the formula:

$\mathrm{Y}$ is the output;

$\mathrm{X}$ is input;

$\mathrm{K}$ is the computing time;

a is filter coefficient, ranging from 0 to 1 .

For the sampling time of $T_{0}$ system, filter coefficients of using the following formula:

$a=e^{-T_{0} / T_{1}}$

In the formula:

$T_{1}$ is the filter time.

$\mathrm{S}$ is the corresponding transfer function, as follows:

$\frac{1}{1+T_{1} S}$

The control algorithm allows the step input to be filtered to obtain a smooth transition curve and adjust the filter time to control the response speed. 

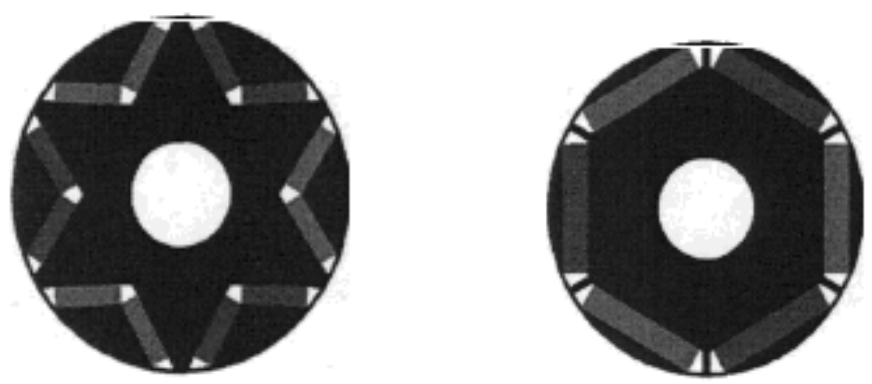

Fig. (5). Embedded radial type rotor structure schematic drawing.
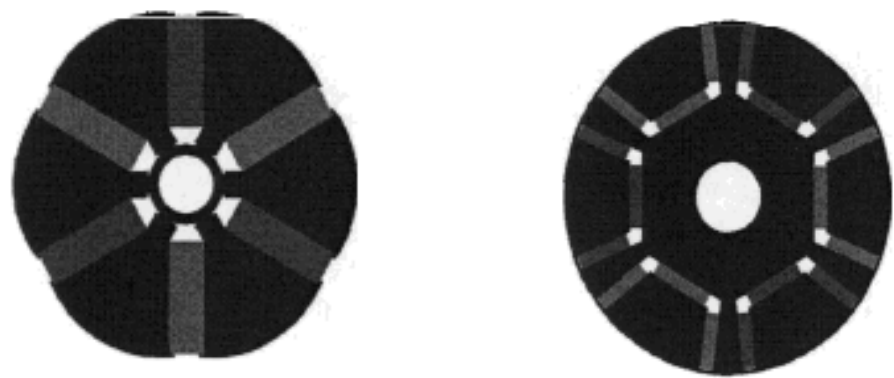

Fig. (6). Embedded tangential type rotor structure schematic drawing.

\subsection{The PID Control Module}

PID algorithm with incremental PID control algorithm:

$u_{k}=u_{k-1}+K_{P}\left(e_{k}-e_{k-1}\right)+K_{i} e_{k}+$

$K_{d}\left(e_{k}-2 e_{K-1}+e_{k-2}\right)$

In the formula:

$U_{K}$ is the output;

$E_{K}$ is the difference between the actual value and the target value;

$\mathrm{Kp}, \mathrm{Ki}$ and $\mathrm{Kd}$ are the proportional, integral and differential coefficients, respectively. In order to avoid system problems caused by saturator saturation in engineering applications, anti-saturation treatment is required. In this algorithm, there are two cases that will trigger a saturation state: the integral output is less than the lower limit of the integral, the input error is less than 0 ; the integral output is greater than the integral lower limit and the input error is greater than 0 . When the trigger input is saturated, the integral input normal error is 0 , so that the integral output is no longer updated. In order to maintain the current state, the maximum or minimum state is required until the input error changes from the saturation state. The anti-saturation algorithm not only limits the maximum and minimum integral outputs, but also has a faster response speed.

\section{THE ROTOR STRESS ANALYSIS AND STRUCTURAL OPTIMIZATION}

According to the magnetization direction of the permanent magnet and the direction of the rotor, the relationship between the rotor structure of the permanent magnet embedded motor is radial, cutting and mixing.

\subsection{Radial Embedded Structure}

This structure has a small magnetic flux leakage coefficient, the rotor has a high mechanical strength, plug-in permanent magnet shape is not easy to change, simple structure, reliable operation and so on. Fig. (5) shows a few radial embedded rotor structure diagrams.

\subsection{Tangential Embedded Structure}

This structure has the advantage of providing a magnetic pole distance between two adjacent poles, each of which can greatly increase the magnetic flux. At the same time, compared with the radial motor rotor structure, the reluctance torque increased significantly. Fig. (6) shows a schematic view of several tangential embedded rotor structures.

\subsection{Mixed Structure}

The structure has the advantages of cutting and radial type rotor structure, but its manufacturing process is more complicated. The structural circuit showing the hybrid embedded rotor magnet is shown in Fig. (7).

\section{THE COMPRESSOR DRIVEN LINK}

In the product delivery system, the drive link is critical to the components of the entire system. Due to the battery voltage level, the power supply voltage drive system will be limited to a certain level. In this paper, the drive voltage 

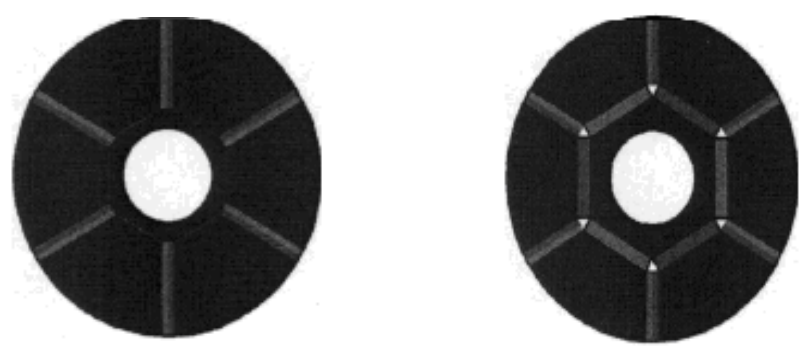

Fig. (7). The built-in hybrid rotor structure schematic drawing.

Table 1. Different voltage grade drive parameters.

\begin{tabular}{|c|c|c|c|c|}
\hline Category & Voltage Level & Voltage Range & Peak Current & Power \\
\hline \multirow{5}{*}{ Low Voltage Series } & 12 & $10-18$ & 120 & 1000 \\
\hline & 24 & $20-32$ & 95 & 1000 \\
\hline & 48 & $38-58$ & 40 & 1200 \\
\hline & 72 & $60-96$ & 25 & 1000 \\
\hline & 96 & $82-110$ & 20 & 1200 \\
\hline \multirow{2}{*}{ High Voltage Series } & 144 & $120-180$ & 16 & 1500 \\
\hline & 288 & $220-320$ & 18 & 2500 \\
\hline
\end{tabular}

design is often present at $12 \mathrm{~V}, 24 \mathrm{~V}, 48 \mathrm{~V}, 72 \mathrm{~V}, 96 \mathrm{~V}$, $144 \mathrm{~V}$ and $288 \mathrm{~V}$, as shown in Table $\mathbf{1}$.

\section{CONCLUSION}

This article has developed a product delivery system using a motor drive system. The system is powered by an embedded permanent magnet brushless DC motor, and the driver uses a position sensorless control technology.

\section{CONFLICT OF INTEREST}

The contents of this study are original and owned by myself, and no one may use it without my permission.

\section{ACKNOWLEDGEMENTS}

This paper belongs to: the project of the "Baoding science and technology research and development plan", No. 14ZG008; "Research project of higher school science and technology in Hebei Province in 2014", No. Z2014164; "Agricultural University of Hebei science and Technology Fund" No. LG20150203.

\section{REFERENCES}

F. X. Wang and L.Y. Xu, "Calculation and measurement of radial and axial force for a bearingless PMDC motor", in Industry Applications Conference, pp. 249-252, 2000.
[2] C. H. Jun and N. A, "Analysis of the mechanical stresses on a squirrel cage induction motor by the finite element method", in IEEE Transactions on Magnetics, vo1. 35, no. 3, part 1, pp. 1282$1285,1999$.

[3] E.C. Lovelace, T. M. Jahns, T. A. Keim, and J. H. Lang, "Mechanical Design Considerations for Conventionally Laminated, HighSpeed, Interior PM Synchronous Machine Rotors", in IEEE Transactions on Industry Applications, vo1. 40, no. 3, pp. 806-812, 2004.

[4] Y K. Kim and J. Lee, "A comparative study of high-speed permanent magnet synchronous motor for air compressor", in INTMAG, pp. 663-664, 2005.

[5] W. -S. Oh, Y. -T. kim, C. -S. Kim, T. -S. Kwon, and H. -J. Kim, "Speed Control of Induction Motor Using Genetic Algorithm Based Fuzzy Controller", in IEEE Industrial Electronics Society Conference, Canada, 1999.

[6] K. W. Lim, T. S. Low, M. F. Rahman, and L. B. Wee, "A Discrete Time Variable Structure Controller for a Brushless DC Motor Drive", in IEEE Transaction on Industrial Electronics, vol. 38, no. 2, pp. 102-107, 1991.

[7] B. Mulgrew, "Applying Radial Basis Functions", in IEEE Signal Processing Magazine, vol. 13, no. 2, pp. 50-65, 1996.

[8] J. Wang, Z. L. Liu, and Y. Chen, "Comparative Analysis of Economic Efficiency of Grain Storage by Solar Absorption Refrigeration", AISS: Advances in Information Sciences and Service Sciences, vol. 4, no. 14, pp. 341-348, 2012.

[9] H. P. Huang and Y. H. Liu, "Fuzzy Support Vector Machines for Pattern Recognition and Data Mining", International Journal of Fuzzy Systems, vol. 4, no. 3, pp. 826-835, 2002.

[10] Y. Lin, Y. Lee, and G. Wahba,"Support Vector Machines for Classification in Nonstandard Situations", Machine Learning, vol. 46, pp. 191-202, 2002

(C) Yu and Fan; Licensee Bentham Open.

This is an open access article licensed under the terms of the Creative Commons Attribution Non-Commercial License (http://creativecommons.org/licenses/by-nc/4.0/) which permits unrestricted, non-commercial use, distribution and reproduction in any medium, provided the work is properly cited. 